\title{
Pengelolaan Lahan Gambut di Perkebunan Kelapa Sawit di Riau
}

\author{
Management of Peatland at Oil Palm Plantation in Riau
}

\author{
Jastri Mey Saragih $^{1}$ Hariyadi $^{{ }^{*}}$ \\ ${ }^{1}$ Departemen Agronomi dan Hortikultura, Fakultas Pertanian, Institut Pertanian Bogor \\ (Bogor Agricultural University), J1. Meranti, Kampus IPB Darmaga, Bogor 16680, Indonesia \\ Telp.\& Faks.62-251-8629353 e-mail agronipb@indo.net.id \\ *Penulis untuk korespondensi: hariyadi@rocketmail.com
}

Disetujui 14 November 2016/ Published online 16 Desember 2016

\begin{abstract}
Both water management and compaction are pre-requisites for successful utilization of peatland for oil palm plantation. Research was conducted at Riau in order to follow the practise of the company in managing peatland for oil palm crop, as well as to study the water management system of estates. Activity was carried out for 4 months from February to June 2013. Target of water level at plantation commonly is in range 25 to $50 \mathrm{~cm}$ below the ground surface. Drainage system consists of main canals, branch canals, new branch canals, collection canals, collection trenches, middle trenches, and field drain. The efforts to maintaining the water level are building up water zoning, installing piezzometers, water gates, over flow gates, water flows, building up emergency gates, installing spillway, treating canals, and making maps and SOP of water management system. Simple linear regression analysis was used to estimate the effect of rainfall to water level. Result showed that the rainfall significantly $(p$ value $=0.014)$ affected the water level. Increasing $1 \%$ of the rainfall would increase the water level by $0.06899 \%$ below the ground surface. Multiple linear regression analysis was used to estimated the effect of rainfall and water level to production. Results showed that the rainfall and the water level did not affect the production.
\end{abstract}

Keywords: compacting, drainage, water level, water management

\begin{abstract}
ABSTRAK
Pengelolaan tata air dan pemadatan tanah merupakan syarat awal pengelolaan lahan gambut di perkebunan kelapa sawit. Kegiatan dilaksanakan di Riau dengan tujuan umum mengetahui dan mengikuti praktek perusahaan dalam mengelola lahan gambut untuk tanaman kelapa sawit, serta dengan tujuan khusus mempelajari sistem pengelolaan tata air perkebunan. Kegiatan dilaksanakan selama 4 bulan mulai Februari - Juni 2013. Pada umumnya sasaran ketinggian air di Perkebunan adalah 25 - $50 \mathrm{~cm}$ di bawah permukaan tanah. Sistem drainase terdiri atas kanal utama, kanal cabang, kanal cabang baru, kanal kolektor, parit kolektor, parit tengah, dan field drain. Upaya-upaya untuk mempertahankan ketinggian air antara lain membuat water zoning, memasang piezzometer, pintu air, over flow gate, pintu air parit tengah, pembuatan emergency gate, pemasangan spillway, perawatan kanal, dan pembuatan peta dan SOP sistem pengelolaan tata air. Analisis regresi linier sederhana dilakukan untuk menduga pengaruh curah hujan terhadap ketinggian air. Kajian menunjukkan bahwa curah hujan berpengaruh nyata $(P$ value $=0.014)$ terhadap ketinggian air. Kenaikan $1 \%$ curah hujan akan menaikkan ketinggian air $0.06893 \%$ di bawah permukaan tanah. Analisis regresi linier berganda dilakukan untuk menduga pengaruh curah hujan dan ketinggian air terhadap produksi. Kajian menunjukkan curah hujan dan ketinggian air tidak berpengaruh nyata terhadap produksi.
\end{abstract}

Kata kunci: drainase, ketinggian air, pemadatan, pengelolaan tata air 


\section{PENDAHULUAN}

Kebutuhan buah kelapa sawit meningkat tajam seiring meningkatnya kebutuhan CPO dunia, seperti yang terjadi dalam beberapa tahun terakhir ini terutama sejalan dengan peningkatan kebutuhan untuk industri turunan dan pengembangan bio energy sebagai alternatif bahan bakar (Ditjenbun, 2012). Peningkatan permintaan terhadap produksi kelapa sawit tersebut di samping menguntungkan juga menjadi tantangan bagi negara Indonesia sebagai salah satu negara pengekspor kelapa sawit karena perlu peningkatan produksi kelapa sawit untuk memenuhi kebutuhan tersebut sedangkan lahan subur untuk pertanian kelapa sawit semakin terbatas. Perluasan lahan kelapa sawit pada lahan marjinal seperti lahan gambut adalah solusi penting dalam meningkatkan produksi kelapa sawit

Lahan gambut merupakan lahan yang potensial untuk tanaman kelapa sawit. Produksi kelapa sawit bisa mencapai $20-25$ ton/ha/tahun, sehingga tidak kalah jika dibandingkan dengan produksi kelapa sawit pada jenis tanah lain (Setiadi, 1999). Menurut Sabiham (2012) luas lahan gambut di Indonesia 15 juta ha dan 9 juta ha sesuai syarat untuk pertanian. Namun yang sudah dibuka dan dikembangkan baru 0.5 juta ha untuk tanaman pangan yang dikelola oleh para transmigran serta 1.2 juta ha untuk perkebunan khususnya kelapa sawit. Menurut winarna (2012) baru 700 - 800 ribu ha lahan gambut digunakan untuk budidaya kelapa sawit dari total luas perkebunan kelapa sawit di Indonesia 7.8 juta ha. Oleh karena itu sangat diperlukan upaya- upaya oimalisasi sumber daya lahan gambut untuk perkebunan kelapa sawit di Indonesia.

Budidaya kelapa sawit pada lahan gambut selalu melibatkan pengelolaan tata air, pemadatan tanah, dan pemupukan, dan jika ketiga faktor tersebut tidak dikelola dengan baik, kelestarian lahan gambut akan terancam. Pengelolaan tata air yang buruk akan berpengaruh secara signifikan terhadap penurunan produksi. Level air yang terlalu rendah akan meningkatkan laju subsiden dan resiko kecelakaan kebakaran gambut. Drainase yang buruk akan menyebabkan kondisi kering tak balik (irreversible). Oleh karena itu pengelolaan tata air adalah syarat awal keberhasilan pengelolaan lahan gambut (Melling dan Hatano, 2010). Kriteria lahan gambut untuk kebun kelapa sawit harus memenuhi Peraturan Menteri Pertanian (PERMENTAN) Nomor 14/Permentan/ PL.110/2/2009 Tahun 2009 (Dean, 2009).

Menurut Hatano et al. (2010) level air merupakan faktor penting dalam menentukan regulasi emisi gas rumah kaca pada tanah gambut. Level air yang semakin rendah akan meningkatkan emisi $\mathrm{CO}_{2}$ dan $\mathrm{N}_{2} \mathrm{O}$, sedangkan kondisi banjir akan menghasilkan emisi $\mathrm{CH}_{4}$.

\section{BAHAN DAN METODE}

Kegiatan dilaksanakan dari bulan Februari - Juni 2013 di Kecamatan Pelangiran, Kabupaten Indragilir Hilir, Riau. Data yang diperoleh berupa data primer maupun data sekunder. Data primer diperoleh dengan pengamatan dan wawancara secara langsung di lapangan, sedangkan data sekunder diperoleh dari arsip perusahaan.

Kegiatan peremajaan (replanting) di lahan gambut dianalisis secara deskripsi. Pengaruh curah hujan terhadap ketinggian air dianalisis dengan uji regresi linier sederhana. Uji regresi sederhana ini dilakukan untuk menduga nilai ketinggian air berdasarkan curah hujan. Model persamaan yang digunakan dalam analisis ketinggian air sebagai berikut:

\section{Keterangan:}

$$
\mathrm{Y}=\alpha+\beta \mathrm{X}
$$

Y : Ketinggian air

A : Konstant titik potong $\mathrm{Y}$, merupakan nilai perkiraan bagi $\mathrm{Y}$ ketika $\mathrm{Y}=0$ (garis $\mathrm{Y}$ memotong sumbu $\mathrm{X}$ )

B : Koefisien regresi atau peubah rata-rata $Y$ untuk setiap satu unit peubahan (naik atau turun) pada variabel $\mathrm{X}$

$\mathrm{X}$ : Curah hujan

Pengaruh curah hujan dan ketinggian air terhadap produksi dianalisis dengan uji regresi linier berganda Uji regresi berganda ini dilakukan untuk menduga nilai produksi berdasarkan curah hujan dan ketinggian air. Model persamaan yang digunakan dalam analisis ketinggian air sebagai berikut:

$\mathrm{X} \quad$ : Produksi

$$
\mathrm{Y}=\alpha+\beta_{1} \mathrm{X}_{1}+\beta_{2} \mathrm{X}_{2}
$$

$\alpha \quad$ : Konstant titik potong Y, merupakan nilai perkiraan bagi $\mathrm{Y}$ ketika $\mathrm{Y}=0$ (garis $\mathrm{Y}$ memotong sumbu $\mathrm{X}$ )

$\beta_{1,} \beta_{2}$ : Koefisien regresi atau peubah rata-rata $Y$ untuk setiap satu unit peubahan (naik atau turun) pada variabel $X$, dengan menganggap variabel independen lainnya konstan

$\mathrm{X}_{1} \quad$ : Curah hujan

$\mathrm{X}_{2} \quad$ : Ketinggian air

\section{HASIL DAN PEMBAHASAN}

\section{Pengelolaan Tata Air}

Menurut Melling dan Hatano (2010).Pengelolaan tata air (water management) merupakan proses perencanaan yang sistematis 
dalam mengorganisasikan dan mengatur pembuangan air melalui permukaan tanah seperti saluran drainase, dan mempertahankan level air pada kisaran yang oimum bagi pertumbuhan tanaman. Sistem pengelolaan tata air harus mampu membuang kelebihan air permukaan maupun subpermukaan dengan cepat pada musim hujan dan dapat menahan air selama mungkin pada musim kemarau.

Perkebunan BNS keseluruhannya adalah tanah gambut dengan kedalaman $3 \mathrm{~m}$ sampai $5 \mathrm{~m}$ dan ketinggian antara $2.0 \mathrm{~m}$ sampai $4.5 \mathrm{~m}$ di atas permukaan laut (dpl). Terendah adalah $\mathrm{km} 00$ dengan ketinggian $2.0 \mathrm{~m}$ dpl dan tertinggi adalah km 15 Kebun Mandah Estate (MDE) dengan ketinggian $4.5 \mathrm{~m}$ dpl. Data tersebut menunjukkan adanya perbedaan ketinggian yang cukup nyata yaitu 2.5 meter sehingga apabila tidak ada pengelolaan tata air, walaupun banjir di $\mathrm{km} 00$ (hilir), bisa kekeringan di Kebun MDE (hulu). Di samping itu, satu-satunya sumber air perkebunan BNS adalah hujan karena tidak ada sumber air seperti pegunungan, sedangkan sumber air seperti sungai mengandung kadar garam yang tinggi. Oleh karena itu sistem pengelolaan air (water management) sangat diperlukan. Air yang terlalu sedikit atau terlalu banyak pada zona perakaran kelapa sawit akan berdampak kurang baik terhadap penyerapan unsur hara dan hasil TBS. Sebagian besar perakaran kelapa sawit terkonsentrasi di $50 \mathrm{~cm}$ lapisan atas tanah gambut. Oleh karena itu zona tersebut tidak boleh jenuh air (Melling dan Hatano, 2010). Hubungan ketinggian air terhadap hasil TBS dapat dilihat pada Gambar 1

Gambar 1 menunjukkan bahwa produksi TBS maksimum akan tercapai pada ketinggian air di $50 \mathrm{~cm}$ sampai $75 \mathrm{~cm} \mathrm{~d}$, namun pada umumnya sasaran ketinggian air di BNS adalah pada 25 sampai $50 \mathrm{~cm}$ di bawah permukaan tanah (d) karena air sistem drainase dimanfaatkan untuk prasarana transportasi dan pengolahan TBS di pabrik. Dengan demikian penurunan ketinggian air yang drastis pada musim kemarau tidak akan menghambat kegiatan transportasi dan pengolahan TBS di pabrik. Dalam satu minggu di musim kemarau ketinggian air dapat mengalami penurunan sebesar $4 \mathrm{~cm}$.

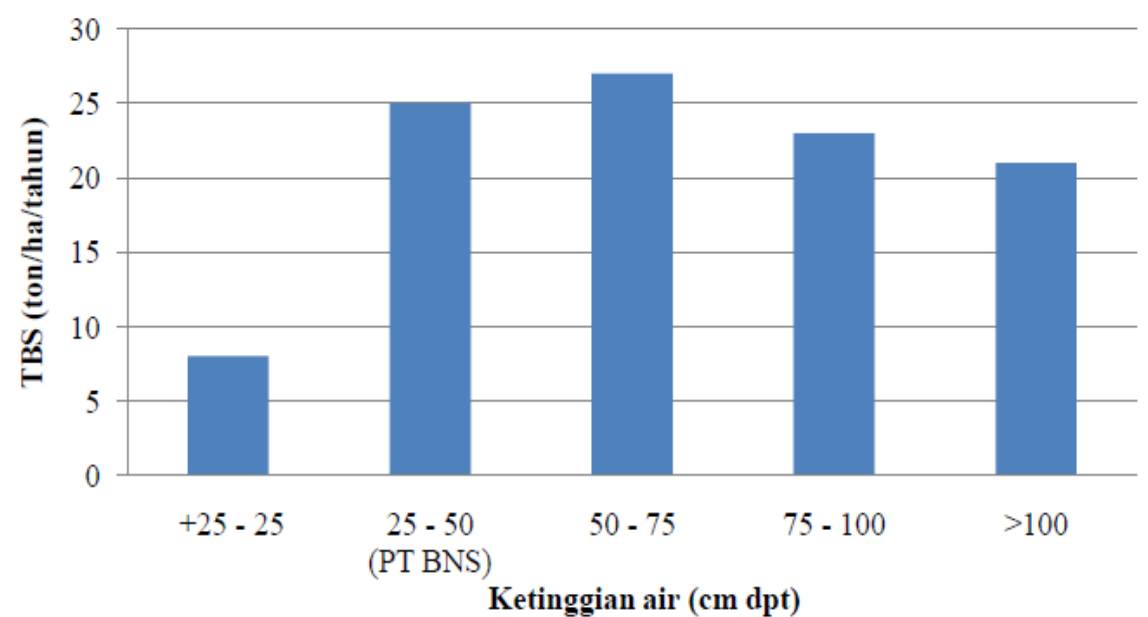

Gambar 1. Hubungan ketinggian air dengan hasil TBS (TM 14) di sebuah kebun gambut di Riau, Sumatera, Indonesia (Huan et al. 2012)

\section{Sistem Drainase}

Drainase harus dirancang dalam bentuk jaringan yang memanfaatkan topografi dan mengalirkan kelebihan air berdasarkan gaya berat. Merancang sistem drainase yang baik harus mengacu pada peta topografi dan bukan berdasarkan visual saja (Pahan, 2012). Sistem jaringan drainase BNS merupakan rekomendasi dari tim research and development.

Perkebunan BNS memiliki sistem drainase yang berbeda dengan sistem drainase lahan gambut di perkebunan kelapa sawit pada umumnya karena di perkebunan ini sistem drainasenya selain dimanfaatkan untuk pembuangan air juga dimanfaatkan untuk prasarana transportasi air. Sistem drainase perkebunan ini terdiri atas kanal utama (KUT), kanal kolektor, kanal cabang (KCB), kanal cabang baru (KCB baru), parit kolektor, parit tengah, dan field drain. Kanal-kanal dan parit kolektor dimanfaatkan untuk prasarana transportasi air sehingga ukurannya lebih luas sedangkan parit tengah dan field drain hanya sebagai saluran pembuangan air. Sistem drainase dapat dilihat pada Gambar 2. 

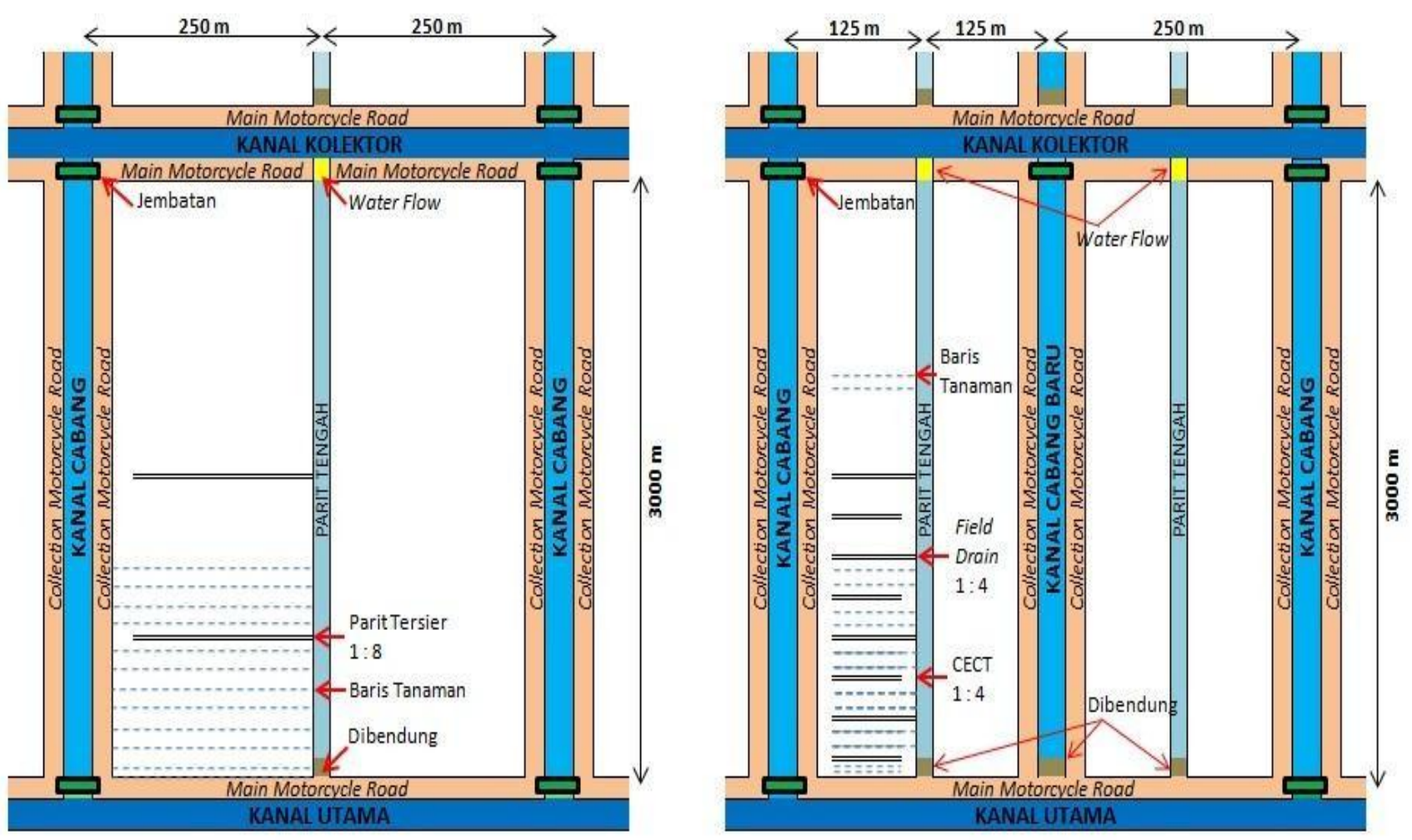

Gambar 2. Layout blok sebelum peremajaan (kiri) dan setelah peremajaan (kanan)

Kanal utama (KUT). Kanal utama merupakan saluran pembuangan akhir sistem drainase sebelum dialirkan ke luar wilayah Perkebunan dan terletak di tengah wilayah perkebunan. Kanal utama juga merupakan prasarana tranportasi TBS dari kebun ke pabrik kelapa sawit (PKS) dan akses keluar masuk perkebunan. Kanal utama langsung bermuara ke sungai sehingga pada muara KUT dipasang pintu air yang disebut spill way agar ketinggian air di KUT tetap terjaga sehingga dapat dilewati kendaraan air. Ukuran KUT ialah $12 \mathrm{~m}$ x $4 \mathrm{~m}$ x 8 m. Kanal utama dilengkapi jembatan penyeberangan.

Kanal kolektor. Kanal kolektor adalah drainase pengumpul air dari $\mathrm{KCB}$ dan mengalirkannya ke KUT melalui KCB tertentu yang topografinya lebih rendah. Kanal kolektor juga merupakan prasarana transportasi TBS dan logistik dari KCB sebelum ke KUT. Ukuran kanal kolektor ialah $12 \mathrm{~m} \mathrm{x} 4 \mathrm{~m}$ x $8 \mathrm{~m}$ dan sejajar dengan KUT. Kanal kolektor dilengkapi jembatan penyeberangan.

Kanal cabang (KCB). Kanal cabang merupakan drainase penghubung Kanal kolektor dengan KUT. Hanya KCB tertentu yang berhubungan langsung dengan KUT sedangkan KCB lainnya dibendung untuk memperlambat aliran air sehingga air lebih lama di dalam blok. Kanal cabang juga merupakan prasarana transportasi pengangkut TBS dari TPH dan logistik ke TPH. Ukuran KCB ialah $4 \mathrm{~m}$ x $2 \mathrm{~m} \times 2 \mathrm{~m}$ dan tegak lurus dengan KUT.

Kanal cabang baru (KCB baru). Kanal cabang baru merupakan kanal yang dibangun di antara dua KCB yang berdekatan dengan ukuran 4 $\mathrm{m} \times 3 \mathrm{~m}$ x $3 \mathrm{~m}$ dan sejajar dengan KCB. Kanal cabang baru dibangun pada area replanting untuk memudahkan akses pengangkutan TBS dari TPH dan logistik ke tengah blok. Kanal cabang baru untuk sementara tidak dihubungkan langsung degan KUT karena dapat mempengaruhi ketinggian air di dalam blok sehingga perlu penelaahan lebih lanjut. Kanal cabang baru dilengkapi jembatan penyeberangan.

Parit tengah. Parit tengah atau pada umumnya disebut parit sekunder adalah drainase pengumpul air dari field drain dan mengalirkannya ke kanal kolektor atau parit kolektor. Parit tengah sejajar dengan KCB dan berukuran $1 \mathrm{~m}$ x $1 \mathrm{~m}$ x 0.8 $\mathrm{m}$. Parit tengah dilengkapi titi berupa balok beton.

Field drain. Field drain atau pada blok sebelum replanting disebut parit tersier adalah drainase dalam blok dan bermuara ke parit tengah. Ukuran field drain ialah $1 \mathrm{~m} \times 0.8 \mathrm{~m} \times 0.8 \mathrm{~m}$. Rasio field drain terhadap baris tanaman adalah 1 : 4. Artinya setiap empat baris tanaman terdapat satu field drain. 


\section{Water Zoning}

Water zoning adalah kawasan yang dikelompokkan berdasarkan topografi dan elevasi yang relatif sama untuk pengelolaan tata air. Masing-masing kebun di BNS memiliki water zoning kecuali kebun TBE karena merupakan hilir. Luas, jumlah, dan posisi water zoning tertera pada peta water zoning. Air water zoning akan mengalir ke KUT TBE melalui KCB tertentu dan kemudian dialirkan ke hilir KUT yang terletak di $\mathrm{km} 00$.

Tujuan pembuatan water zoning adalah mengurangi percepatan aliran air sehingga air kanal pada musim kemarau tidak cepat turun. Aliran air diperlambat dengan cara membuat bendungan di sekeliling water zoning dan mengalirkannya hanya melalui kanal-kanal tertentu sehingga air kanal pada water zoning keluar secara perlahan. Jika musim hujan, air yang berlebih dalam water zoning akan dialirkan melalui pintu air yang langsung mengarah ke laut atau sungai.

Bendungan water zoning terdiri atas bendungan KCB dan bendungan kolektor. Bendungan yang terdapat pada $\mathrm{km} 0.5$ bagian barat KUT atau biasa disebut bendungan $\mathrm{km} 0.5$ merupakan bendungan utama. Bendungan $\mathrm{km} 0.5$ menjadi bendungan terakhir sistem drainase perkebunan yang berfungsi untuk menahan air di hilir KUT sebelum dibuang ke laut sehingga secara tidak langsung bendungan $\mathrm{km} 0.5$ berfungsi sebagai penahan air seluruh sistem drainase perkebunan.

\section{Pengaturan Ketinggian Air}

Ketinggian air di lapangan harus dijaga agar tidak kekeringan di musim kemarau atau kebanjiran di musim hujan. Kebanjiran akan menghambat proses pemanenan sehingga memperlambat rotasi panen. Kondisi ini menyebabkan kehilangan (losses) akibat buah tinggal atau busuk. Kekeringan menyebabkan ketinggian air di kanal rendah atau bahkan kering sama sekali sehingga tidak bisa dilewati kendaraan air pengangkut TBS. Kondisi ini menyebabkan kehilangan akibat TBS tidak terangkut (restan). Upaya-upaya pengaturan ketinggian air (Water Level Control) antara lain memasang piezzometer, membuat pintu air, over flow gate, emergency gate, spillway, membuat peta water zoning, dan merawat kanal secara berkala.

Pemasangan piezzometer. Piezzometer merupakan alat pengukur ketinggian air yang terbuat dari pipa paralon yang berdiameter 3 inchi, panjang 2 meter, dan dilengkapi skala. Piezzometer dipasang di titik tertentu pada bendungan, KUT, $\mathrm{KCB}$, emplasemen, pintu air, over flow gate, emergency gate, spillway, dan pabrik. Sasaran ketinggian air yang terbaca pada masing-masing piezzometer berbeda-beda bergantung posisi ditempatkannya piezzometer. Pada umumnya sasaran ketinggian air pada hulu lebih rendah daripada hilir. Seperti piezzometer di km 5 kebun TBE yang merupakan hilir memiliki sasaran ketinggian air $40 \mathrm{~cm}$ sampai $60 \mathrm{~cm}$ d, sedangkan di km 18 kebun RSE yang merupakan hulu memiliki sasaran ketinggian air 50 sampai $80 \mathrm{~cm} \mathrm{~d}$. Hal ini ditujukan untuk mencegah kekeringan pada kebun yang berada di hulu atau kebanjiran pada kebun yang berada di hilir akibat perbedaan topografi. Informasi ketinggian air yang terbaca pada piezzometer dilaporkan setiap hari ke kantor besar kebun TBE melalui radio. Data ketinggian air menjadi acuan pengaturan ketinggian air.

Pemasangan pintu air (water gate). Pintu air adalah alat untuk mengatur ketinggian air dengan cara membuka dan menutup aliran air. Pintu air pada umunya ditempatkan di setiap hilir kanal yang menuju ke luar wilayah water zoning ataupun ke luar wilayah perkebunan. Setiap pintu air dilengkapi piezzometer. Perkebunan BNS memiliki 1 pintu air perbatasan water zoning dan 4 pintu air perbatasan dengan masyarakat. Pintu air perbatasan masyarakat akan membuang kelebihan air ke sungai atau laut.

Pemasangan over flow gate. Over flow gate adalah alat untuk mengatur ketinggian air dengan cara menahannya pada ketinggian tertentu dan bersifat tetap. Jika air berlebih, secara otomatis air akan mengalir melalui over flow gate. Over flow gate terdapat di titik tertentu pada perbatasan dengan okupasi.

\section{Pemasangan pintu air parit tengah (Water} Flow). Pintu air parit tengah dipasang di setiap pertemuan parit tengah dengan kanal atau parit kolektor. Gunanya untuk mengatur ketinggian air di tengah blok.

Pembuatan emergency gate. Emergency gate merupakan pintu darurat untuk mencegah banjir pada kebun. Emergency gate dapat berupa kanal maupun pintu air yang menghubungkan kebun dengan sungai atau laut.

Pemasangan spillway. Spillway merupakan pintu air utama yang berfungsi untuk mengatur ketinggian air di KUT. Spillway juga berfungsi untuk mencegah penetrasi air laut ke KUT sehingga kadar garam pada KUT tetap sangat 
rendah untuk digunakan pabrik untuk mengolah TBS. Spillway terletak di km 0.45 sebelah barat KUT dan berbatasan langsung dengan sungai. Spillway memiliki 8 pintu air yang menggunakan drat. Spillway dilengkapi piezzometer dengan sasaran ketinggian air $25 \mathrm{~cm}$ sampai $40 \mathrm{~cm} \mathrm{~d}$.

Perawatan kanal. Semua sistem drainase kebun harus tercatat secara administrasi baik jumlah maupun panjangnya. Hal ini ditujukan untuk memudahkan kegiatan perawatan kanal. Setiap tahunnya diadakan pencucian kanal $30 \%$ dari total keseluruhan. Tujuan pencucian kanal antara lain untuk mengoimalkan fungsi kanal baik untuk tanaman maupun kendaraan air, memperlancar sirkulasi air untuk menekan pertumbuhan gulma air terutama lumut (Bryophyta sp.), dan mencegah terganggunnya kipas balingbaling kendaraan air. Pencucian kanal dapat dilakukan secara mekanik dan manual.

Pencucian kanal secara mekanik menggunakan excavator long arm untuk KUT dan short arm untuk KCB dan kanal kolektor. Pencucian dilakukan dengan cara penggalian kembali sedimentasi dari dasar kanal ke luar secara periodik. Kegiatan ini dilakukan saat kondisi air cukup dan kanal tidak boleh digali terlalu dalam (melebihi kedalaman awal) karena dapat menimbulkan longsor. Excavator long Arm (PC>200/seri 9) memiliki PK 3 meter/BU untuk KUT, Excavator short arm (PC 200/seri 7) memiliki PK 5 meter/BU untuk kanal kolektor, dan Excavator short arm (PC 200/seri 7) memiliki PK 10 meter/BU untuk KCB.

Pencucian kanal secara manual menggunakan bargas lumut, cangkul, dan parang. Bargas lumut merupakan kendaraan air yang dikhususkan untuk kegiatan pencucian kanal. Bargas lumut memiliki PK bergantung pada kondisi kerapatan gulma pada kanal. Yang perlu dibersihkan dari kanal adalah lumut, eceng gondok (Eichhornia crassipes), dan sampah, sedangkan tanaman sarung buaya (Ischaemum timorense) perlu dikendalikan pertumbuhannya dengan cara dibabat. Semak-semak di tepi kanal juga dibersihkan dengan cara dibabat.

Pencucian kanal secara biologis dilakukan dengan cara memelihara ikan kowan (Tenenepharyngodon idellus) pada kanal-kanal sebagai pemakan lumut atau algae (Tallophyta sp.). Cara ini masih perlu pengembangan lebih lanjut oleh departemen R \& D Minamas Plantation. Pencucian kanal secara kimia tidak dilakukan karena dapat mengancam kehidupan biota air dan lingkungan.
Pembuatan peta dan SOP (Standard Operational Procedure) Sistem Pengelolaan tata air. Perkebunan BNS memiliki peta umum sistem pengelolaan tata air dan setiap kebun kecuali kebun TBE memiliki peta detail sistem pengelolaan tata air kebun masing-masing. Peta umum hanya mengambarkan kanal-kanal, water zoning, posisi piezzometer, pintu air, spill way, bendungan, dan pengukur curah hujan (ombrometer), sedangkan peta detail termasuk menggambarkan arah aliran air dan muara outlet air. Pemetaan ini memudahkan pengawasan dan penanganan yang tepat waktu.

Ruang lingkup SOP meliputi kegiatan pemeriksaan, pengukuran, pencatatan, perawatan, dan evaluasi terhadap pengelolaan tata air. Tujuan pembuatan SOP antara lain: (1) untuk memonitor ketinggian air di kebun sehingga dapat dipertahankan pada kondisi oimum bagi tanaman, (2) mengumpulkan data-data yang akurat dan terpadu yang berhubungan dengan pengelolaan tata air, (3) apabila ada masalah dengan ketinggian air maka cepat diketahui dan dilakukan usaha-usaha perbaikan, (4) menciakan koordinasi antar kebun maupun PKS dalam penanganan pengelolaan tata air BNS.

\section{Pengaruh Curah Hujan terhadap Ketinggian Air}

Curah hujan merupakan salah satu faktor yang perlu diperhatikan dalam pengaturan ketinggian air di lahan gambut. Hubungan antara curah hujan dengan level air dapat dilihat pada Gambar 3.

Peramalan pengaruh curah hujan terhadap ketinggian air dapat dijelaskan pada model berikut ini:

Level air $=46.52-0.06893$ curah hujan

Hasil analisis regresi linier sederhana menunjukkan nilai signifikan $0.014(<0.05)$ yang artinya curah hujan berpengaruh nyata terhadap ketinggian air pada taraf 5\%. Kenaikan $1 \%$ curah hujan akan menaikkan ketinggian air $0.06893 \%$ di bawah permukaan tanah (Gambar 3). Menurut Harahap et al. (2010) terdapat korelasi positif yang tinggi antara curah hujan dengan ketinggian air.

Nilai $\mathrm{R}^{2}$ sebesar $33.8 \%$ yang artinya curah hujan berpengaruh sebesar $33.8 \%$ terhadap kenaikan ketinggian air dari permukaan tanah (Gambar 3). Sekitar 66.2\% dipengaruhi oleh faktor lain yang tidak dianalisis dalam model. Ketinggian air akan naik akibat tersumbatnya pintu air dengan lumut dan sampah pada musim hujan, namun ketinggian air akan rendah karena pintu air yang bocor pada musim kemarau. 


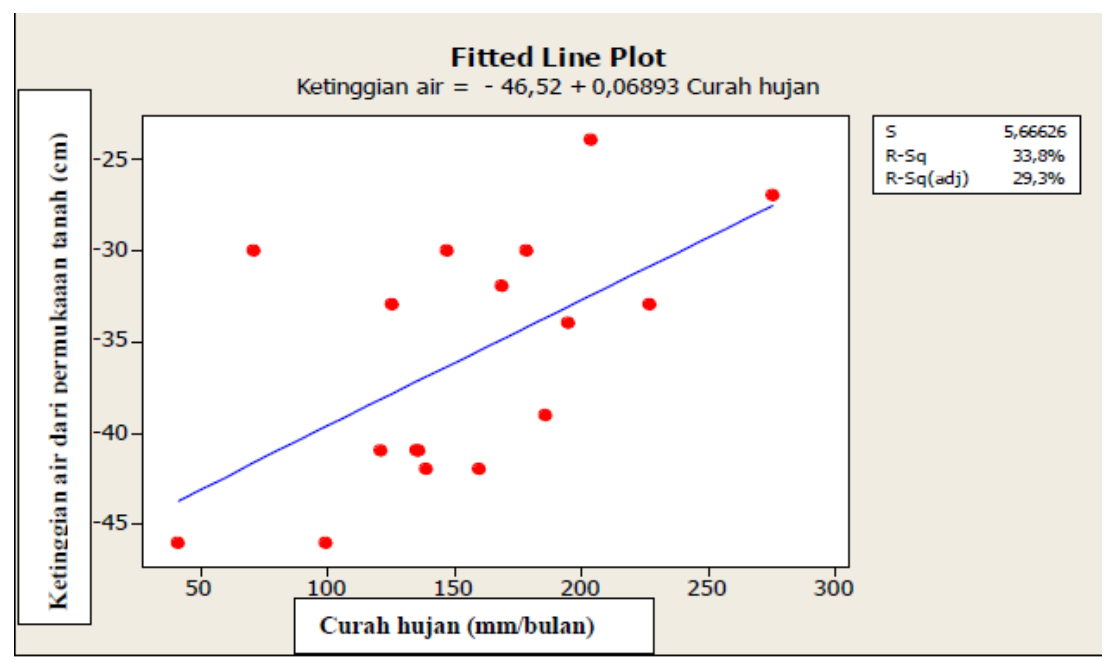

Gambar 3. Hubungan curah hujan dengan ketinggian air periode Januari 2012 - Mei 2013

Gambar 4 menunjukkan bahwa pada Desember 2012 ketinggian air sebesar $24 \mathrm{~cm} \mathrm{~d}$ melebihi batas maksimal ketinggian air. Hal ini mengindikasikan bahwa kapasitas sistem pintu air dalam membuang kelebihan air belum dapat mengimbangi curah hujan yang tinggi $(>200 \mathrm{~mm})$ dari bulan Oktober sampai Desember dalam waktu 24 jam. Jika dilihat data per harinnya, bahkan 8 hari berturut-turut dalam bulan Desember ketinggian air di atas $18 \mathrm{~cm} \mathrm{~d}$. Meskipun demikian, secara keseluruhan ketinggian air di kebun terkontrol dengan baik terutama pada musim kemarau ketinggian air tidak lebih rendah dari batas minimum. Penambahan kapasitas pintu air dalam membuang air dan pembuatan pintu darurat banjir diharapkan dapat mengatasi kelebihan air pada curah hujan yang tinggi (>200 mm).

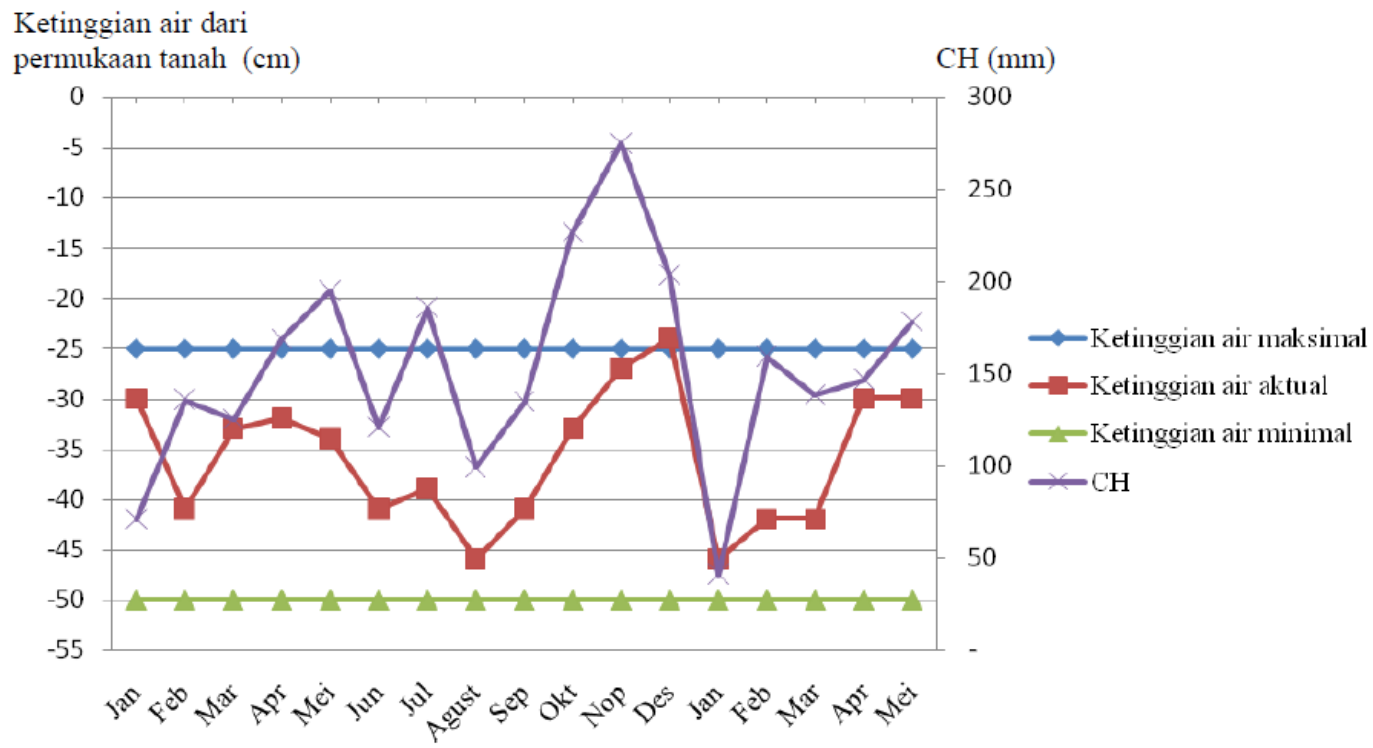

Gambar 4. Ketinggian air dan curah hujan periode Januari 2012 - Mei 2013

\section{Pengaruh Curah Hujan dan Ketinggian Air terhadap Produksi}

Curah hujan mengakibatkan ketinggian air berfluktuatif. Pengelolaan tata air mengupayakan curah hujan dan fluktuasi ketinggian air tidak berdampak pada produksi kelapa sawit. Grafik curah hujan, ketinggian air, dan produksi dapat dilihat pada Gambar 5. Hasil analisis regresi linier berganda menunjukkan nilai signifikansi curah hujan dan ketinggian air terhadap produktivitas sebesar 0.649 dan 0.591. Artinya curah hujan dan fluktuasi ketinggian air tidak berpengaruh nyata terhadap produktivitas. Hal ini menunjukkan sistem pengelolaan tata air di kebun TBE dikelola dengan baik. Hal ini menunjukkan kondisi pintu air dalam keadaan baik. Produksi kebun TBE ialah $17886 \mathrm{~kg}$ TBS/ha/tahun yang terdiri atas TM 18 20. Produksi ini tergolong kelas III pada lahan mineral. Menurut Dja'far et al. dalam 
Hardjowigeno (1996) produksi kelapa sawit pada lahan mineral dapat dikelompokkan sebagai: kelas I>24 ton TBS ha/tahun, kelas II $19-24$ ton TBS/ha/tahun, kelas III 13 - 18 ton TBS/ha/tahun, dan kelas IV $\leq 12$ ton TBS/ha/tahun. Produksi kelapa sawit pada tanah gambut umumnya adalah 12 - 18 ton TBS/ha/tahun. Produksi maksimum umumnya tercapai pada umur 15 tahun, kemudian menurun seperti halnya pada tanah mineral.

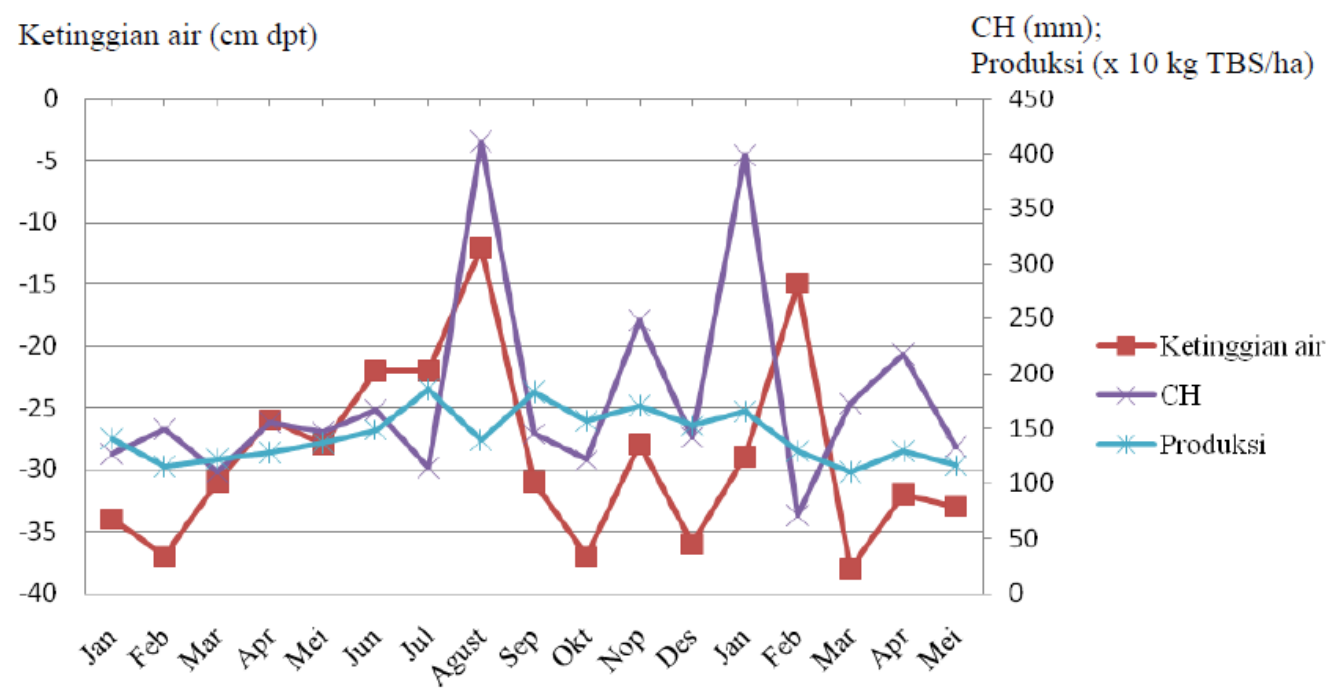

Gambar 5. Ketinggian air dan curah hujan (Januari 2010 - Mei 2011) serta produktivitas (Januari 2012 - Mei 2013)

\section{KESIMPULAN}

Prinsip pengelolaan tata air adalah membuang kelebihan air pada musim hujan dan mempertahankan ketinggian air pada musim kemarau. parit kolektor, parit tengah, dan field drain. Upaya untuk mempertahankan ketinggian air antara lain membuat water zoning, memasang piezzometer, pintu air, over flow gate, pintu air parit tengah, pembuatan emergency gate, pemasangan spillway, perawatan kanal, SOP sistem pengelolaan tata air, dan pembuatan peta.

\section{DAFTAR PUSTAKA}

Dja'far, Abbas, B.S., Angkat, J. 1989. Komperatif produktivitas tanah gambut dengan tanah mineral terhadap produksi kelapa sawit. Di dalam: Prosiding Seminar Tanah Gambut untuk Perluasan Pertanian. Dalam Hardjowigeno, S.1996. Pengembangan Lahan Gambut untuk Pertanian Suatu Peluang dan Tantangan. Orasi Ilmiah Guru Besar Tetap Ilmu Tanah Fakultas Pertanian Institut Pertanian Bogor.

[DEPTAN] Departemen Pertanian Republik Indonesia. 2009. Peraturan Menteri Pertanian Nomor 14/Permentan/PL.110/ 2/2009 Tahun 2009 [Internet]. [diunduh 9 Okt 2013]. Tersedia pada http://ppvt. setjen. dean.go.id.
Gomez, K.A., Gomez, A.A. 1995. Prosedur Statistik untuk Penelitian Pertanian Edisi Kedua. Sjamsuddin E, Baharsjah JS, penerjemah. Jakarta (ID): UI pr. Terjemahan dari: Statistical Procedures for Agricultural Research.

Harahap, I.Y, Hidayat, T.C, Lubis, E.S., Pangaribuan, Y., Sutarta, E.S. 2010. The dynamical water table deh in oil palm plantation and its region. In: Proceedings International Oil Palm Conference 2010: Environment \& Social Economics. Medan (ID): Pusat Penelitian Kelapa Sawit (PPKS).

Hatano, R., Inoue, T., Yamada, H., Sato, S., Darung, U., Limin, S., Limin, A., June, T., Suwardi, Sumawinata, B. 2010. Soil greenhouse gases emissions from various land uses in tropical peatlands in Indonesia. Proceeding of Palangkaraya International Symposium \& Workshop On Tropical Peatland. Department of Soil Science and Land Resources Building Bogor Agricultural University. 
Huan, P.L.K., Lim, S.S., Parish, F., Suharto, R., editor. 2012. RSPO Manual On Best Management Practices (BMPs) for Existing Oil Palm Cultivation On Peat. Kuala Lumpur (MY): RSPO (Roundtable on Sustainable Palm Oil).

Huan, L.K., Wahyudi, H. 2010. Management of leaning and fallen palms planted on tropical peat. In: Proceedings International Oil Palm Conference 2010: Agriculture. Medan (ID): Pusat Penelitian Kelapa Sawit (PPKS).

Melling, L., Hatano, R. 2010. Sustainable utilization of tropical peatland for oil palm plantation. Proceeding of Palangkaraya International Symposium \& Workshop On Tropical Peatland. Department of Soil Science and Land Resources Building Bogor Agricultural University.

Pahan, I. 2012. Panduan Lengkap Kelapa Sawit Manajemen Agribisnis dari Hulu hingga Hilir. Bogor (ID): Penebar Swadaya.
Sabiham, S. 2012. Lahan Gambut: Maslahat atau Mudharat. Seminar Forum Wartawan Pertanian [internet]. [diunduh 27 Jan 2013]. Tersedia pada http://disbun. kaltimprov.go.id.

Setiadi, B. 1999. Teknologi Pemanfaatan Lahan Gambut untuk Pertanian. Dalam Setiadi B dan Nugrahadi D. Masalah dan Prospek Pemanfaatan Gambut. Dalam Barchia, MF. 2006. Gambut: Agroekosistem dan Transformasi Karbon. Yogyakarta (ID): UGM press.

Winarna. 2012. Lahan Gambut: Maslahat atau Mudharat. Seminar Forum Wartawan Pertanian [internet]. [diunduh 27 Jan 2013].Tersedia pada http://disbun. kaltimprov.go.id.

Yanuar. 2011. Ekspor kelapa sawit terus naik. [internet]. [diunduh 23 Okt 2013]. Tersedia pada http://ditjenbud.dean.go.id. 